\title{
基于车载激光雷达的道路病害检测技术研究
}

鲍彦奇 ${ }^{12}$ 韩尚兵 ${ }^{12}$ 陈风琳 ${ }^{12}$

1 天水三和数码测绘院有限公司 2 甘肃省测绘工程技术研究中心

DOI:10.32629/gmsm.v3i3.693

[摘 要] 随着我国经济的飞速发展, 公路道路建设也跟着快速发展, 在这同时公路的保养维护工作变的越来越重要。但传统人工检测道路病害 的方法效率低下,已完全不能满足公路养护的要求, 因此迫切需要一种快速检测道路病害的技术。本文以车载激光雷达在道路病害检测中的应用 为例, 叙述不同种类道路病害的提取,为类似道路病害检测中车载激光雷达的应用提供了参考。

[关键词] 车载移动测量系统; 道路病害; 提取

车载移动测量系统是一款集激光扫描仪、高清CCD相机、GPS、惯导单 元IMU等传感器的先进地理数据采集系统, 它能够在快速行进中获取到高精 度、高密度的公路路面点云数据及与之匹配的影像数据。常规道路检测作 业手段单一, 单靠密集的劳动力远远无法满足当前社会道路病害检测维护 需求, 本文将从道路路面数据的快速获取、处理及对道路病害自动化提取等 方面, 利用车载激光雷达技术等构件满足道路病害检测需要的解决方案。
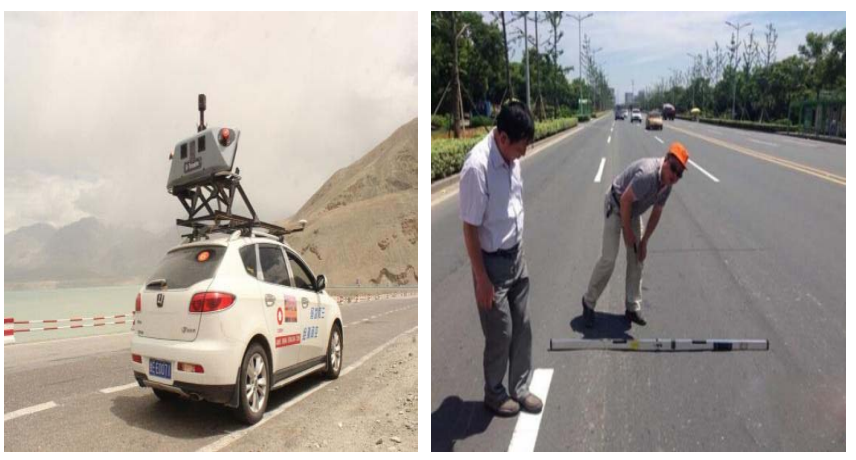

图1 作业方法对比

1 车载移动测量系统及工作原理

1.1 车载移动测量系统

车载移动测量系统一般由高精度激光扫描测量系统、组合导航系统、 全景相机及相应软件组成, 是数字图像传感技术、惯性组合定位定姿技术、 激光扫描技术和全景成像技术等发展与结合的产物, 它所涉及的理论与技 术都是当前信息技术发展的前沿, 代表着未来道路测量的发展主流。

1.2 三维激光扫描仪工作原理

三维激光扫描仪通过测距观测值s, 激光脉冲横向角度 $\alpha$ 和纵向角度 $\theta$, 三维激光扫描仪相位中心为原点, $X$ 轴在横向扫描面, $Y$ 轴在横向扫描面与 $X$ 轴垂直, Z轴与横向扫描面垂直, 得到测量点的坐标, 测量点计算公式如下 图2所示:

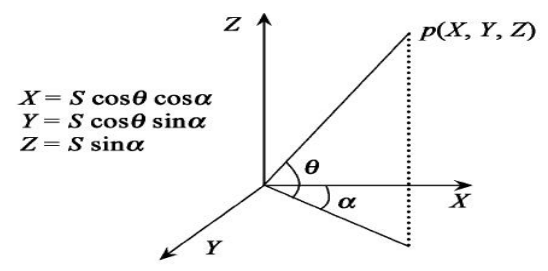

图2 三维激光扫描仪测量原理

\section{2 数据获取及处理}

2. 1 道路病害数据获取

目前, 传统的道路病害检测技术手段单一, 作业人员在马路上会有安
全隐患, 在影响交通的情况下作业难度大, 作业效率低, 基于车载移动测量 系统光学影像和激光点云数据分析的路面病害自动检测技术是一种无损 检测技术。利用车载移动测量系统数据获取的高效性、高密度性和无接触 性的优势, 能在不影响现有交通运营的情况下, 既可大大减少外业作业工 作量、工作难度, 提高作业效率, 又能保障作业人员的安全性。因此, 利用 插在移动测量系统获取道路病害数据更为高效, 可以克服各种作业困难, 为获取高精度道路病害数据提供技术保障。作业流程如图3:

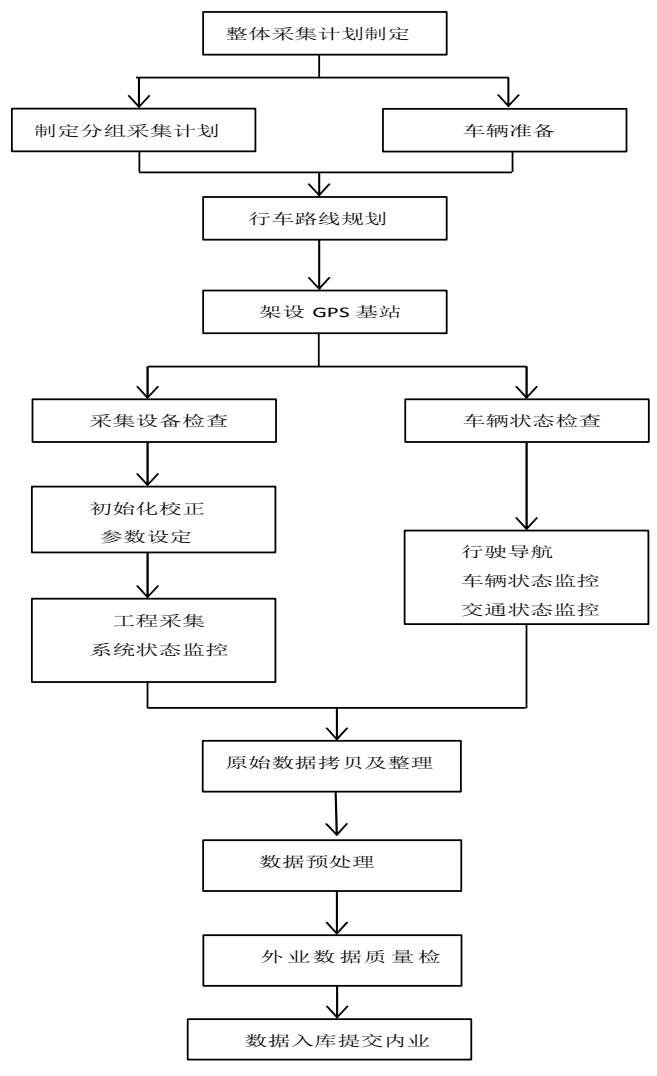

图3 外业作业流程图

2.1.1数据采集系统。数据采集系统包括高精度三维激光扫描系统、 360 全景相机和工业相机。三维激光扫描系统能够快速的获取高精度点云数 据, 点云根据标定的参数和提供的位置姿态信息可以转换成绝对坐标。 360 全景相机由 6 个工业相机组成, 可以对通过的道路及两边的地物拍摄, 经过 配准的相机可以将照片中的RGB信息赋予到对应的点云上面, 得到与地物 一致的真实彩色点云; 通过软件控制实时显示车载移动测量系统激光脉冲 的发射数量以及回收到的数量。 
2. 1. 2高精度POS系统。高精度POS系统包括GNSS天线, IMU惯性导航单 元, DMI车轮编码器以及POS 计算机部分组成, 系统采集到基站GPS数据, 高 频率的惯性导航单元数据及车轮编码器数据经差分处理、惯性数据集成处 理后, 得到车辆高动态行驶过程中的位置和姿态数据。

2. 2 道路病害数据处理

2. 2. 1数据预处理。数据采集完成后需要对数据进行预处理才能得到 准确坐标的点云数据。数据预处理包括POS数据 (定姿定位数据, 包括 $\mathrm{GPS}$ 定位数据、IMU定姿数据和DMI辅助定位数据) 解算、轨迹校正、点云数据 解算, 通过事后差分软件, 使用精确的基站数据校正车载移动测量系统获 取的POS数据, 经过正反向运算, 最大提高POS数据精度。

2.2.2道路病害数据提取。通过使用道路病害提取专题软件, 基于三维 激光点云和配准过得全景影像进行病害自动化提取, 辅助以手动提取自动 化之外的部分, 可对裂缝、坑槽、车辙印等多种病害进行识别和提取。

(1) 裂缝类病害。在高精度三维激光点云的基础上, 参照全景影像提取 道路路面裂缝, 记录路面裂缝长度、宽度属性信息, 检校过的设备可以让裂 缝的提取精度达到毫米级。

(2) 坑槽、沉陷病害。坑槽、沉陷类变形病害形变量比较大, 三维激 光点云中与周边点云沉陷明显, 易于区分、识别并提取出来, 对于疑似的 沉陷、坑槽病害可利用全景影像及辅助工业相机拍摄的高清路面影像进 行查找和提取。另外点云剖面可以对病害的最大深度进行计算, 完善道 路坑槽、沉陷类病害属性信息。

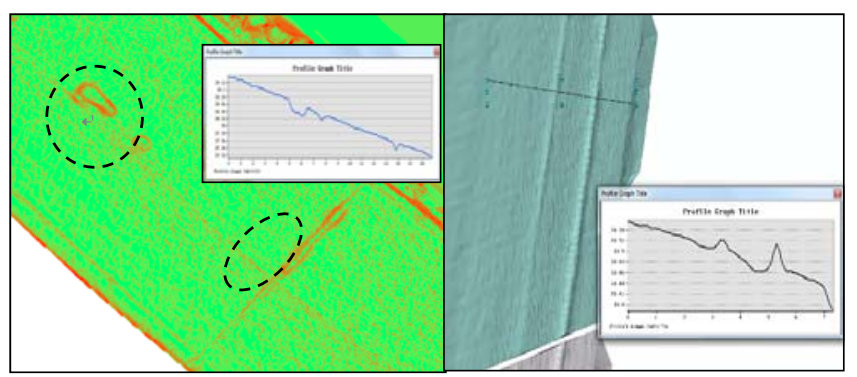

图4 坑槽与沉陷
根据自动化提取以及手动提取道路病害, 输出依照《公路沥青路面养 护设计规范》 (JTG 5421-2018) 中病害样式及注记标准制作病害符号绘制 路面病害分布专题图并建立对应的数据库文件方便识别和管理。

将道路病害数据导入应用管理平台, 全景数据与地理信息地图服务相 融合, 实现数据成果资源应用, 可视化、可操作管理, 车载三维激光扫描系 统的全景相机经过配准, 照片的RGB色彩赋到点云上面形成真实彩色点云, 然后将三维激光点云跟全景照片导入管理平台, 全景照片和三维激光点云 相融合, 得到可量测的街景, 现在信息化平台都会提供手机移动端服务, 可 以针对道路病害外业核查成为常规作业手段, 效率更高。

\section{3 结论}

本文所提及的车载移动测量系统在道路病害检测中的应用, 比传统手 段更加方便、有效率, 为公路道路检测养护带来了全新的技术手段, 设备不 仅在城市道路检测得到了成功应用, 在智慧城市、街景、林业普查监测、 城市立面改造等诸多领域都可以推广使用。

[参考文献]

[1]易延光,黄洪彬.车载移动测量系统的构成与应用 [J]. 黑龙江水利 科技,2011,(03):284-285.

[2]谢成. 大数据下智能交通系统的发展综述 [J]. 通讯世 界,2019,26(07):187-188.

[3] 韩光瞬, 冯仲科,刘永霞, 等.三维激光扫描系统测树原理及精度分析 [J].北京林业大学学报,2005,(S2):187-190.

[4]唐德利, 李兆雄. 车载移动测量系统点云误差分析及修正[J].地理空 间信息,2016,(08):33-35+4.

[5]王永红, 陈宏强,杨晓锋, 等.车载移动测量系统在市政管线地形图测 量中的精度分析[J].测绘通报,2017,(05):82-84+99.

作者简介:

鲍彦奇(1993--), 男, 甘肃天水人, 汉族, 助理工程师,2016年本科毕 业于山东科技大学测绘工程专业,之后一直在天水三和数码测绘院有 限公司和甘肃省测绘工程技术研究中心(2016年任职)从事激光扫描测 量技术及其应用的研究。 